\title{
Lateral diffusion of a human sperm-head antigen during incubation in a capacitation medium and induction of the acrosome reaction in vitro
}

\author{
S. Villarroya and R. Scholler \\ Fondation de Recherche en Hormonologie, 67 boulevard Pasteur, 94260 Fresnes and \\ 26 boulevard Brune, 75014 Paris, France
}

\begin{abstract}
Summary. An integral component of human spermatozoa, a glycoprotein of $M_{\mathrm{r}}$ 143000 (two subunits of $M_{\mathrm{r}} 76000$ and 67000 ) was recognized by the a-HS $1 \mathrm{~A} .1$ monoclonal antibody. The antigen was localized on the plasma membrane over the sperm head, as demonstrated by transmission electron microscopy. The antigenantibody binding on gametes during changes in their functional state was followed by an indirect immunofluorescence assay of live human spermatozoa. In freshly ejaculated spermatozoa the antibody binding pattern revealed a patchwork quilt-like topography of the plasma membrane over the acrosome; the percentage of positive cells varied from 20 to $78 \%$ with a mean of $50 \%(n=82)$. Incubation in a capacitation medium could increase this percentage up to $98 \%$, revealing new epitopes in an energy-dependent and temperature-independent manner; concomitantly, a part of the antigen migrated in energy-independent and temperature-dependent manner and accumulated in a ring over the postacrosome. When an acrosome reaction was induced in vitro in the presence of $\mathrm{Ca}^{2+}$ with either A23187, ionomycin or human follicular fluid, the HS 1A.1 antigen migrated until immobilization in a well defined pattern around the equatorial segment (single band) or around the equatorial and postacrosomal segments ( 2 or, seldom, 3 bands). The new antigen localization resulted from a lateral diffusion of pre-existing molecules, occurred in only a few minutes, did not require energy and was temperaturedependent. At the same time, the well outlined large patch burst into a multitude of small spots before vanishing. This veil-like labelling was often observed in spermatozoa kept in the seminal plasma or treated with a metabolic poison.

The HS 1A.1 antigen localization reflects surface changes induced by the incubation in a capacitation medium and the acrosome reaction. Apart from the regional heterogeneity of the plasma membrane of a single cell, as noted above, there were differences in the plasma membrane changes in individual spermatozoa from the same ejaculate as well as in semen samples from different donors. The new antibody binding pattern was often alike in successive ejaculates of the same donor. In patients consulting for infertility the percentage of positive cells was often low and migration of the antigen was slight or absent.
\end{abstract}

\section{Introduction}

Over the past two decades there has been considerable advance in the knowledge of membrane structure. In 1972, Singer \& Nicolson proposed the fluid mosaic model in which both proteins and lipids are free to diffuse in the bilayer, implying a random organization of protein and lipids. However, many of the proteins of biomembranes do not float independently in an indifferent lipid bilayer. The restriction of cell surface molecules into discrete domains is established in a wide 
variety of mammalian cell types and for several proteins (Fujita et al., 1973; Wisher \& Evans, 1975; Wall \& Hubbard, 1981; Anderson et al., 1982; McCaig \& Robinson, 1982; Primakoff \& Myles, 1983 ) and lipids (Friend, 1982; Karnovsky et al., 1982; Wolf et al., 1986).

The membrane topography may reflect the functional geometry of the cell and also be important in the regulation of cell surface function. The spermatozoon is one of the cell types in which regional differentiation was demonstrated (for reviews see Bedford \& Cooper, 1978; Koehler, 1978, 1981; Yanagimachi, 1981; Nicolson, 1982; Bellvé \& O'Brien, 1983). Using monoclonal antibodies, we have demonstrated that particular antigens are restricted in a minimum of 6 domains on live human spermatozoa (Villarroya \& Scholler, 1986a). One of them, HS 1A.1 antigen, localized on the plasma membrane over the acrosome, might be involved in subtle changes occurring during capacitation, and might help to visualize the loss of the acrosomal cap during the acrosome reaction. In human spermatozoa the acrosome is small, unlike that of the guinea-pig or hamster, and the acrosome reaction cannot be visualized readily by light microscopy.

In this paper, we report redistribution of this antigen during incubation in a capacitation medium and induction of the acrosome reaction in vitro; the relocation is accompanied by an antigen accumulation in specific patterns around the equatorial and posterior segments. This change in the antigen localization results from the migration of surface molecules. Some parameters characterizing this rearrangement and the recognized antigen are investigated. Part of this work has been reported in abstract form (Villarroya \& Scholler, 1986b).

\section{Materials and Methods}

Monoclonal antibody. Mouse-mouse hybridomas were obtained by a fusion between SP 2/0 myeloma cells and spleen cells from a mouse immunized with washed human spermatozoa; monoclonal antibodies were selected on their positive response against live human spermatozoa as previously described by Villarroya \& Scholler (1986a).

Human spermatozoa. Ejaculated semen samples were obtained from healthy donors or out-patients consulting for infertility at the Fondation de Recherche en Hormonologie, after 2-3 days of sexual abstinence. Spermatozoa were allowed to liquefy at $37^{\circ} \mathrm{C}$ for $0.5-1 \mathrm{~h}$ and normal samples $\left(20-250 \times 10^{6}\right.$ spermatozoa/ml, $>50 \% \mathrm{motility}$ and $>60 \%$ normal morphology) were gently washed twice in Medium BWW (Biggers et al., 1971), 0.3\% bovine serum albumin, fraction V (BSA, Miles Scientific, Naperville, IL, U.S.A.). This and subsequent BWW media were supplemented with $20 \mathrm{~mm}$-Hepes. At this step the spermatozoa were considered as freshly ejaculated.

Motile spermatozoa were separated from those with low or no motility by the migration-sedimentation method of Tea et al. (1983), which increased up to $98 \%$ the percentage of motile cells. The migration was performed in Medium $\mathrm{BWW}+3 \% \mathrm{BSA}$ for $3 \mathrm{~h}$. Unless otherwise stated, this and subsequent incubations were performed at $37^{\circ} \mathrm{C}$ in an atmosphere of $5 \% \mathrm{CO}_{2}$ in air.

In-vitro capacitation and acrosome reaction. In this paper the term 'capacitation' should be interpreted as 'in-vitro incubation in a capacitation medium'. Washed spermatozoa were resuspended in capacitation medium (Medium $\mathrm{BWW}+3 \% \mathrm{BSA}$ ) at up to $10 \times 10^{6} \mathrm{cells} / \mathrm{ml}$. Substituting human albumin, fraction V (Sigma Chemical Co., St Louis, MO, U.S.A.) for BSA in any medium used did not improve or change the results. Aliquants were removed at intervals ranging from 0.5 to $18 \mathrm{~h}$ and processed. To determine the extracellular calcium ion dependence, cells were washed in $\mathrm{Ca}^{2+}$-free medium and incubated in: (1) $\mathrm{Ca}^{2+}$-free Medium BWW, 1.25 mm-ethylenediaminetetraacetic acid (EDTA, Merck) or (2) Medium BWW supplemented with calcium chloride concentrations ranging from $1 \cdot 7$ to $30 \mathrm{mM}$.

The acrosome reaction of spermatozoa at $10 \times 10^{6} / \mathrm{ml}$ concentration was induced in the presence of $\mathrm{Ca}^{2+}$ with: (1) the divalent cation ionophore A23187, free acid (Sigma), 1-100 $\mu \mathrm{M}$ final concentration from a $\times 100$ stock solution in dimethylsulphoxide (DMSO, Sigma); (2) the calcium ionophore ionomycin, calcium salt (Calbiochem, Behring Diagnostics, La Jolla, CA, U.S.A.), 1-100 $\mu \mathrm{M}$ final concentration from a $\times 1000$ stock solution in ethanol; (3) human follicular fluid, 100 or $500 \mu \mathrm{l}$. At different times (from $5 \mathrm{~min}$ to $2 \mathrm{~h}$ ) aliquants were washed and immunolabelled.

Immunostaining by indirect immunofluorescence assay. Live human spermatozoa were immunolabelled with the a-HS 1A.I monoclonal antibody and fluorescein isothiocyanate (FITC)-conjugated goat anti-mouse IgG (GAM, Institut Pasteur Production, Marnes-la-Coquette, France) as previously reported (Villarroya \& Scholler, 1986a). Incubations with the antibody were performed for $1 \mathrm{~h}$ at room temperature $\left(20-22^{\circ} \mathrm{C}\right)$ or overnight at $4^{\circ} \mathrm{C}$. For each preparation, 200 cells or more were scored. 
Electron microscopy. Immunolabelling was performed as above, the second antibody being a 1:50 dilution of peroxidase-conjugated sheep anti-mouse IgG (Institut Pasteur Production). Washed cells were then fixed for $30 \mathrm{~min}$ in $1 \%$ glutaraldehyde in cacodylate buffer $(0 \cdot 1 \mathrm{M}$-sodium cacodylate- $\mathrm{HCl}, \mathrm{pH} 7 \cdot 3,0 \cdot 2 \mathrm{M}$-sucrose $)$ and processed as described by Huneau et al. (1984), except that $0.35 \%$ potassium ferrocyanide was added to the osmium tetroxide in order to enhance the membrane contrast. Ultrathin sections were viewed with a Zeiss EM 10 electron microscope.

Immunoprecipitation. To avoid the radioiodination step in the classical immunoprecipitation method, we set up the following protocol. Human spermatozoa $\left(100 \times 10^{6}\right)$ were incubated for $1 \mathrm{~h}$ at room temperature with $250 \mu \mathrm{l}$ a-HS 1A.1 monoclonal antibody in the presence of $1 \mathrm{~mm}$-phenylmethylsulphonyl fluoride (PMSF, Merck) and $1 \mathrm{mM}$ $p$-aminobenzamidine ( $p$-AB; Sigma). Cells were washed twice in buffer NET (150 mM-NaCl, $5 \mathrm{~mm}$ - EDTA, $50 \mathrm{~mm}$ Tris-HCl pH 7.5, I mM-PMSF, 1 mM- $p$-AB) and then solubilized in lysis buffer (150 mM- $\mathrm{NaCl}, 50 \mathrm{~mm}$-Tris- $\mathrm{HCl}$ $\mathrm{pH} 7.5,1 \%$ Triton-X-100, $1 \mathrm{~mm}-\mathrm{PMSF}, 1 \mathrm{~mm}-\mathrm{p}-\mathrm{AB})$ for $1 \mathrm{~h}$ on ice. Nuclei and cell debris were removed by centrifugation in a Beckman Microfuge $\left(10000 \mathrm{~g}, 10 \mathrm{~min}, 4^{\circ} \mathrm{C}\right)$, the antigen-antibody complex was immunoprecipitated for 20 min on ice with $100 \mu \mathrm{l}$ of $10 \%$ Protein A-Sepharose CL-4B (Pharmacia Fine Chemicals, Uppsala, Sweden) in lysis buffer and washed (twice in lysis buffer, twice in NET buffer). The pellet was resuspended in sample buffer (125 mMTris- $\mathrm{HCl} \mathrm{pH} \mathrm{6.8,} \mathrm{4 \%} \mathrm{(w/v)} \mathrm{sodium} \mathrm{dodecyl} \mathrm{sulphate} \mathrm{(SDS),} 20 \%(\mathrm{w} / \mathrm{v})$ glycerol, $5 \%$ (v/v) 2-mercaptoethanol, heated at $100^{\circ} \mathrm{C}$ for $5 \mathrm{~min}$ and centrifuged to eliminate the Sepharose beads.

SDS-polyacrylamide gel electrophoresis (PAGE). SDS PAGE was performed according to the method of Laemmli (1970) in 1.5-mm thick slab acrylamide gel $\left(10 \% \mathrm{~T}, 1.3 \% \mathrm{C}_{\text {bis }}\right.$ for the running gel and $5 \% \mathrm{~T}, 2.5 \% \mathrm{C}_{\mathrm{bis}}$ for the stacking gel). Gels were calibrated by high and low molecular weight standards (Bio-Rad Laboratories, Richmond, CA, U.S.A.). A control for the migration of the monoclonal antibody, obtained by immunoprecipitation of $20 \mu \mathrm{l}$ antibody supernatant, was run simultaneously. Gels were fixed for at least $3 \mathrm{~h}$ in $50 \%(\mathrm{v} / \mathrm{v})$ ethanol, $10 \%(\mathrm{v} / \mathrm{v})$ acetic acid, and silver stained.

Silver staining. Gels were stained by an improved procedure, based on the papers of Morrissey (1981), Eschenbruch \& Bürk (1982) and Heukeshoven \& Dernick (1985). Fixed gels were: (1) washed thoroughly to obtain neutral conditions as nearly as possible, i.e. $4 \times 15 \mathrm{~min}$ in $10 \%(\mathrm{v} / \mathrm{v})$ ethanol, and then $3 \times 10 \mathrm{~min}$ in distilled water; (2) soaked for $30 \mathrm{~min}$ in 1,4-dithiothreitol (DTT, Merck), $5 \mu \mathrm{g} / \mathrm{ml}$; (3) without rinsing, treated for $30 \mathrm{~min}$ in $0.1 \%$ $\mathrm{AgNO}_{3}$; (4) rapidly rinsed in distilled water and developed in $2.5 \% \mathrm{Na}_{2} \mathrm{CO}_{3}$ solution containing $50 \mu \mathrm{l} 37 \%$ formaldehyde $100 \mathrm{ml}$ ( 2 changes) until the desired level of staining was attained; (5) soaked for $10 \mathrm{~min}$ in $0.05 \%$ citric acid, $50 \mu$ aqueous methylamine $(35 \%) / 100 \mathrm{ml}$ and washed off under running water. All solutions were filtered through nitrocellulose filters and gloves were used to handle gels, glass plates and solutions.

Glycoproteins were stained: (1) as described by Dzandu et al. (1984) with the modification that the second step of Coomassie brilliant blue R 250 staining was omitted or replaced by silver staining as described above; (2) after treatment with $0.7 \%$ periodic acid in $40 \%$ ethanol, $5 \%$ acetic acid for $5 \mathrm{~min}$ and washing $3 \times 15 \mathrm{~min}$ in distilled water, steps $2-5$ were performed as above.

\section{Results}

\section{Localization of the HS 1 A.1 antigen in freshly ejaculated human spermatozoa}

Freshly ejaculated washed human spermatozoa, immunostained with the a-HS 1A.1 monoclonal antibody, had an acrosome outlined in discontinuous manner, or patches scattered over the anterior head, mainly on the apical region (Fig. 1, Al and Fig. 2,1). The brightness of the fluorescence, the size of the spots and the percentage of positive cells showed individual variability. The latter varied from 20 to $78 \%$ with a mean of $50 \%(n=82)$. A rough calculation estimated the patch size as between 0.25 and $4 \mu \mathrm{m}^{2}$. The binding pattern and the labelled subpopulation were the same whether live spermatozoa were stained at room temperature $\left(20-22^{\circ} \mathrm{C}\right)$ or at $4^{\circ} \mathrm{C}$, and when three aliquants from the same semen sample were processed in parallel and when different smears were made from the same aliquant. The antigen recognized by the a-HS 1A.1 monoclonal antibody was localized on the plasma membrane as demonstrated by electron microscopy (Fig. 3,1).

\section{Localization changes}

After in-vitro capacitation and $\mathrm{Ca}^{2+} / \mathrm{A} 23187$ treatment, different antigen localizations could be observed (Fig. 1). Besides the distribution over the acrosome (A), fluorescence could be visualized on the postacrosome as either a sharp fluorescent ring, often perceived as bright regular little spots on both extremities $(\mathrm{P})$, a widespread more or less bright and more or less regular band over the 


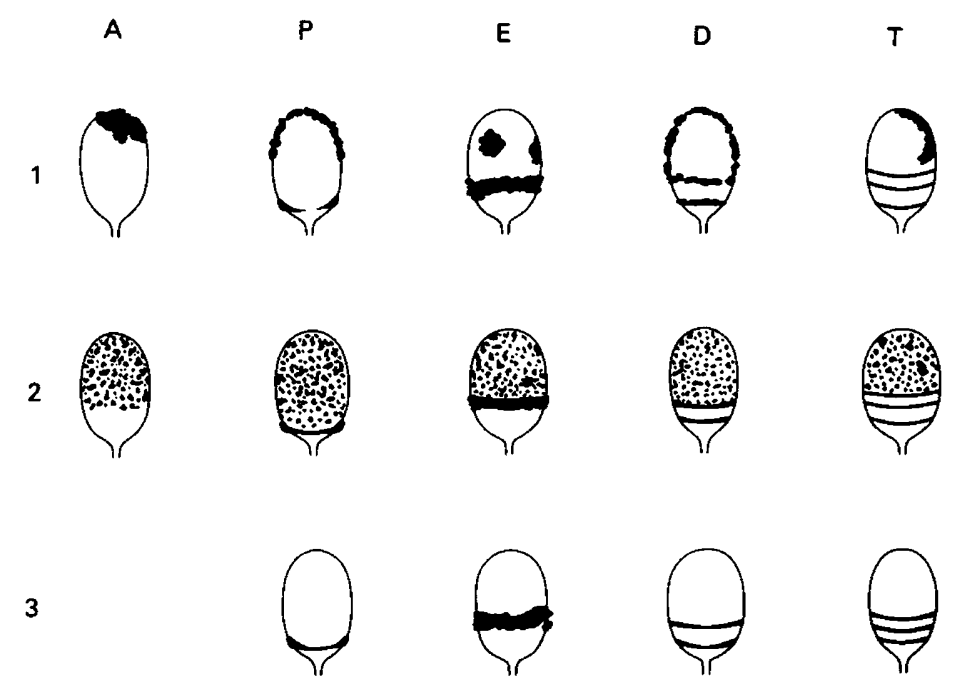

Fig. 1. Schematic representation of the different binding patterns of the a-HS $1 \mathrm{~A} .1$ monoclonal antibody on live human spermatozoa. For more details, see the text.

equatorial segment (E), two distinct bands on the postacrosome ( $\mathrm{D}$ for double band), or even as three distinct bands on the postacrosome ( $T$ for triple band). The last antibody binding pattern was observed in only a few spermatozoa from 4 semen samples out of more than 100 human ejaculates, and so it does not appear in the figures where the distribution of each pattern is given. A large, well outlined patch, or patches, was present over the acrosomal segment for E, D and T labelling or over the acrosomal and postacrosomal segments for P labelling (1); a multitude of extremely small spots, sometimes visible like a veil, was scattered on the whole acrosome (2) and more or less small spots, i.e. intermediate between the large patch and the veil, were observed; neither large nor small spots were present (3). Figure 2 represents microphotographs of human spermatozoa illustrating these patterns. In transmission electron microscopy the antigen was always viewed on the plasma membrane, notwithstanding its localization over the sperm head (Fig. 3).

\section{Antibody binding after sperm incubation in a capacitation medium}

When left briefly in the seminal plasma or at the beginning of the incubation in a capacitation medium, the large fluorescent spots were localized over the anterior segment, the equatorial segment (Fig. 2,2 and Fig. 3b) and even over the postacrosome. After incubation for $18 \mathrm{~h}$ the percentage of labelled cells could increase up to $98 \%$ and concomitantly the percentage of P1 labelled cells increased (Figs 2, 5 and 13). After an overnight incubation in seminal plasma, many spermatozoa displayed A2 and P2 labelling (Figs 2, 4 and 6).

Immunostaining of highly motile spermatozoa or those of low motility or non-motile showed that the antigen was mainly distributed on the acrosome of motile cells. Furthermore, on the latter the size of the spots was greater and the fluorescent label was brighter than on immotile spermatozoa. The percentage of immunostained motile spermatozoa increased gradually with time of migration, whereas those of low motility and non-motile remained unchanged.

The migration of the antigen on the postacrosome and the increase of the percentage of positive cells showed variability between men (Table 1). The patterns illustrated by Patients 1 and 2, with an antigen migration and an augmentation of the positive subpopulation, and by Patient 3 , with only 
a redistribution of the antigen, were the most usual. Less frequent were the patterns shown by Patients 4 and 5.

For an individual ejaculate the increase of the positive subpopulation and the antigen migration were similar in capacitation media with $\mathrm{Ca}^{2+}$ concentration ranging from 1.7 to $10 \mathrm{~mm}$; these changes were not present or only slight with incubation in the absence of $\mathrm{Ca}^{2+}$ (Fig. 4). Incubation in $30 \mathrm{~mm}-\mathrm{Ca}^{2+}$ provoked a decrease of the size of the positive subpopulation in some spermatozoa (Fig. 5).
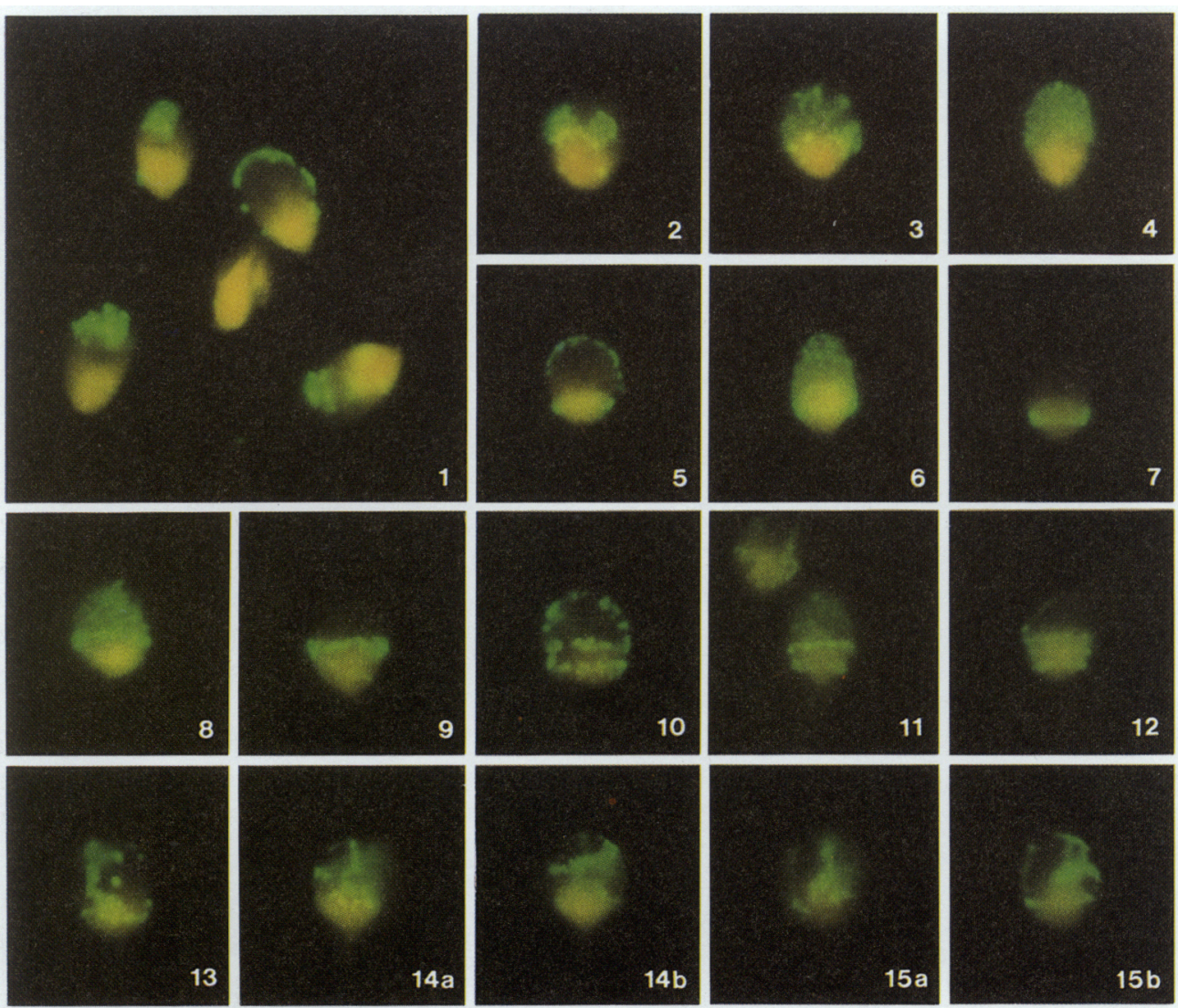

Fig. 2. Localization of the HS 1A.1 antigen on live human spermatozoa. The yellow-orange staining of nuclei is produced by p-phenylenediamine. The anterior head is darker than the posterior one on the slides and non-perceptible on these photographs. The antibody binding patterns are visualized by FITC-GAM. Note the diversity in size and localization of large patches. As indicated in Fig. 1, the labelling is Al on the head top (1) and over the equatorial segment (2); intermediate between A1 and A2 (3); A2 (4); P1 (5); P2 (6); P3 (7); E2 with remains of a large patch (8); E3 (9); DI, probably at the start of formation of the two rings (10); D2 (11); TI with very faint acrosome labelling (12); PI with arborescent migration of the antigen from the anterior head down to the posterior one (13). In the last four photographs (a) and (b) represent an infinitesimal variation in the focussing on the same cell. An arborescent propagation down to the postacrosome (14a) and a sidewise diffusion (14b) are seen. A part of the antigen moves down until reaching the $\mathrm{P}$ labelling (15a), another part migrates transversally around the equatorial segment $(15 \mathrm{~b})$. Original magnification $\times 1600$, total magnification $\times 4500$. 

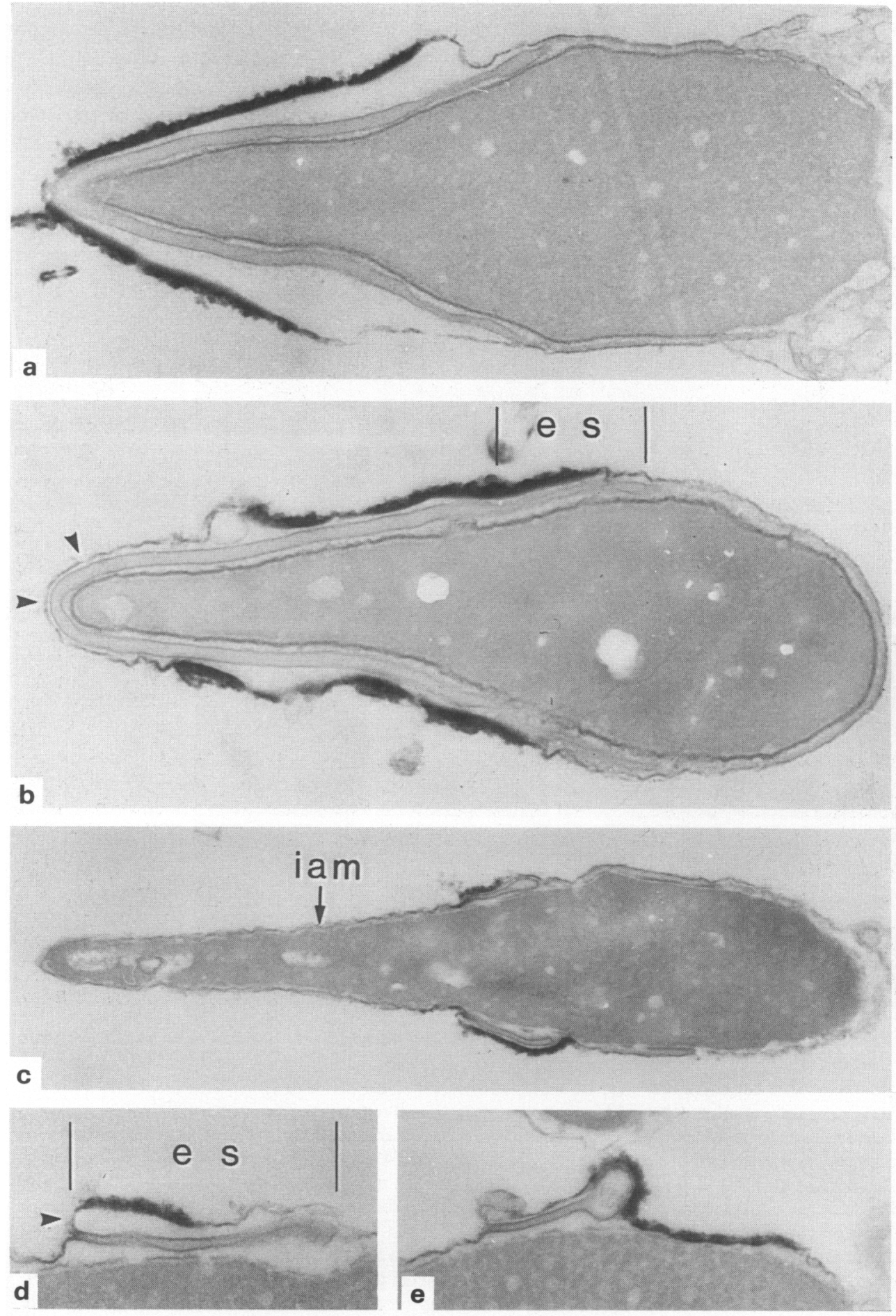
Table 1. Some examples of changes detected by indirect immunofluorescence in the size of the positive subpopulation and a-HS 1A.1 antibody binding pattern of human spermatozoa, freshly ejaculated or incubated in a capacitation medium for $3 \mathrm{~h}$

\begin{tabular}{llccc}
\hline & & \multicolumn{3}{c}{ Percentage of labelled cells } \\
\cline { 3 - 4 } & & \multicolumn{2}{c}{ Antigen localization } \\
\cline { 3 - 4 } & & \multicolumn{3}{c}{$\begin{array}{c}\text { Acrosome and } \\
\text { postacrosome }\end{array}$} \\
\multirow{2}{*}{ Patient } & Acrosome & Total \\
\hline 1 & Spermatozoa & (A1) & (P1) & 53 \\
& Freshly ejaculated & 53 & 0 & 82 \\
2 & Capacitated & 61 & 21 & 35 \\
3 & Freshly ejaculated & 32 & 3 & 78 \\
4 & Capacitated & 41 & 37 & 64 \\
4 & Freshly ejaculated & 52 & 12 & 67 \\
& Capacitated & 25 & 42 & 60 \\
5 & Freshly ejaculated & 36 & 24 & 92 \\
& Capacitated & 67 & 25 & 51 \\
& Freshly ejaculated & 50 & 1 & 54 \\
\hline
\end{tabular}

An experiment, detailed in Table 2, was performed to investigate whether the change in the antibody binding pattern was the result of antigen diffusion. Experiment $A$ showed the antibody binding before in-vitro capacitation. Experiment $B$ revealed the relocation of epitopes pre-existing on freshly ejaculated spermatozoa. Experiment $C$ tested the possibility that new epitopes, by insertion or unmasking or transformation, were detected. When spermatozoa with non-tagged antigen were capacitated and then immunostained, the pattern and percentages were similar to those in Exp. C; apparently the antigen-antibody complex was able to rearrange as freely as the antigen alone.

Another experiment, run in parallel, was performed to test the possibility that during the incubation the bound monoclonal antibody dissociates and recognizes new epitopes. Spermatozoa, stained with the monoclonal antibody followed by FITC-GAM, were capacitated in Medium BWW containing a 10-fold excess of the a-HS 1A.1 antibody. If during the incubation new molecules were inserted or unmasked on the postacrosome, no fluorescence would be seen there because of the competition with the non-fluorescent antibody in excess. In two different ejaculates the binding pattern and the percentage of positive cells were similar to that in Exp. B, and we concluded that the HS 1A.1 antigen actually migrates from the acrosome to the postacrosome.

Fig. 3. Transmission electron microscopy pictures of the subcellular localization of the HS 1A.1 antigen on the plasma membrane. Freshly ejaculated human spermatozoon with labelling over the anterior segment of the acrosome, $\times 35000$ (a). In capacitated spermatozoa the antigen is localized over the equatorial segment (e s) and the anterior segment without the apical region (arrowhead), $\times 36000$ (b). After $\mathrm{Ca}^{2+} / \mathrm{A} 23187$ treatment the acrosomal cap is no longer seen, the exposed inner acrosomal membrane (iam) is not labelled, the antigen is distributed over the equatorial segment (e s), $\times 26000$ (c) and $\times 41000$ (d); the fusion (arrowhead) of the outer acrosomal membrane with the plasma membrane at the anterior edge of the equatorial segment is evident (d). Labelling of the postacrosomal region in an acrosome-reacted spermatozoon, $\times 36000(\mathrm{e})$. 
Fig. 5

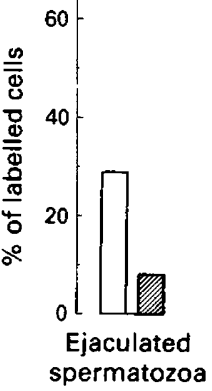

$3 \mathrm{~mm} \quad \mathrm{Ca}^{2+}$

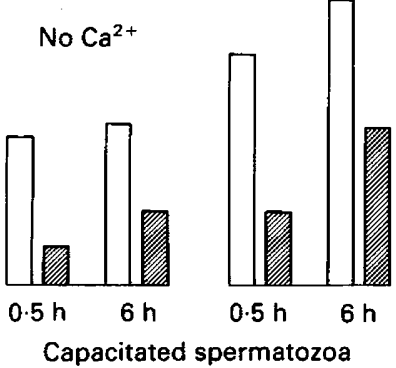

(1)

(2)

(3)

(4)
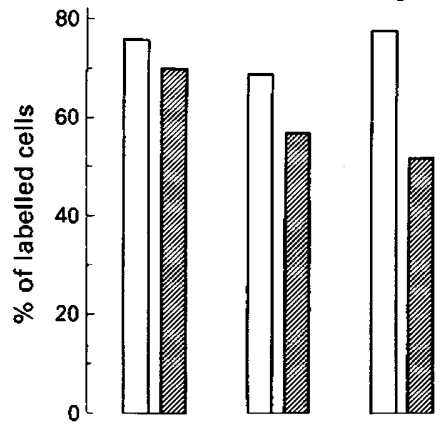

Fig. 4. Effects of extracellular calcium ion on antigen migration and of the increase of the positive subpopulation during incubation in a capacitation medium, observed in 5 semen samples; data from only one is presented. The antigen was visualized on the acrosome (A1 labelling, open bars) and on the acrosome + postacrosome (P1 labelling, closed bars) after different periods of incubation at $37^{\circ} \mathrm{C}$ in the absence or presence of $\mathrm{Ca}^{2+}$.

Fig. 5. Individual donor responses in the effect of increased extracellular calcium ion concentration. Washed human spermatozoa from four different ejaculates $(1,2,3,4)$ were capacitated at $37^{\circ} \mathrm{C}$ for $3 \mathrm{~h}$ in Medium BWW $+3 \% \mathrm{BSA}$ and $3 \mathrm{~mm}$ (open bars) or $30 \mathrm{~mm}$ (closed bars) $\mathrm{Ca}^{2+}$.

Table 2. Migration of the HS 1 A.1 antigen during in-vitro capacitation: freshly ejaculated human spermatozoa from three different semen samples $(1,2,3)$ were tagged with the monoclonal antibody and aliquants were then stained with FITCGAM (A), washed, incubated in capacitation medium at $37^{\circ} \mathrm{C}$ for $3 \mathrm{~h}$, and stained with FITC-GAM (B), or washed, incubated in capacitation medium, washed, and incubated with the monoclonal antibody followed by FITC-GAM (C)

\begin{tabular}{|c|c|c|c|c|}
\hline \multirow[b]{3}{*}{ Patient } & \multirow[b]{3}{*}{$\begin{array}{c}\text { Sperm } \\
\text { processing }\end{array}$} & \multicolumn{3}{|c|}{ Percentage of labelled cells } \\
\hline & & \multicolumn{2}{|c|}{ Antigen localization } & \multirow[b]{2}{*}{ Tota } \\
\hline & & $\begin{array}{c}\text { Acrosome } \\
\text { (A1) }\end{array}$ & $\begin{array}{l}\text { Acrosome and } \\
\text { postacrosome } \\
\text { (P1) }\end{array}$ & \\
\hline 1 & $\begin{array}{l}\text { A } \\
\text { B } \\
\text { C }\end{array}$ & $\begin{array}{l}54 \\
30 \\
39\end{array}$ & $\begin{array}{r}5 \\
27 \\
34\end{array}$ & $\begin{array}{l}59 \\
57 \\
73\end{array}$ \\
\hline 2 & $\begin{array}{l}\text { A } \\
\text { B } \\
\text { C }\end{array}$ & $\begin{array}{l}48 \\
18 \\
28\end{array}$ & $\begin{array}{r}4 \\
33 \\
41\end{array}$ & $\begin{array}{l}52 \\
51 \\
69\end{array}$ \\
\hline 3 & $\begin{array}{l}\text { A } \\
\text { B } \\
\text { C }\end{array}$ & $\begin{array}{l}43 \\
27 \\
45\end{array}$ & $\begin{array}{r}7 \\
26 \\
27\end{array}$ & $\begin{array}{l}50 \\
53 \\
72\end{array}$ \\
\hline
\end{tabular}




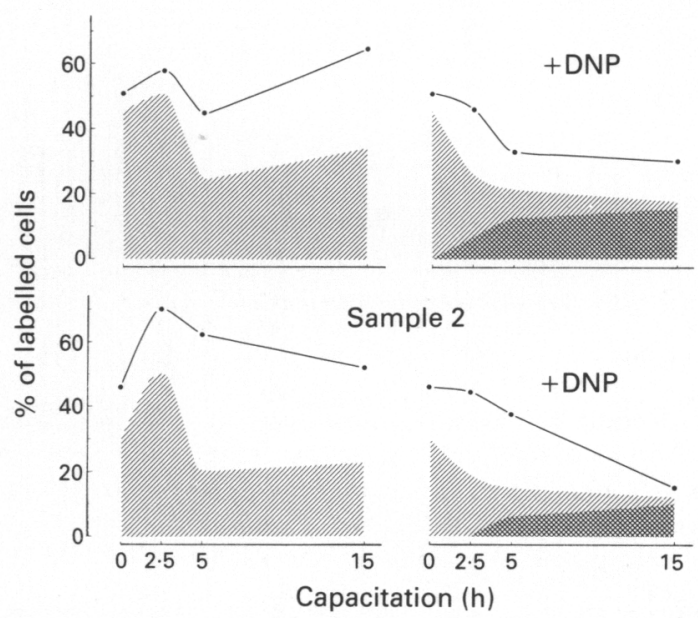

Fig. 6. Energy dependence of phenomena occurring during incubation in a capacitation medium and revealed by the a-HS $1 \mathrm{~A} .1$ antibody binding pattern. Two ejaculates (1 and 2) were capacitated in Medium BWW $+3 \%$ BSA at $37^{\circ} \mathrm{C}$ in the absence or presence of $10 \mathrm{~mm}$ dinitrophenol (DNP). At the times shown aliquants were removed and immunostained. The populations of A1 (国) and A2 (图) labelled cells are visualized as a part of the total percentage (-), the difference representing the percentage of P, E and D labelled cells.
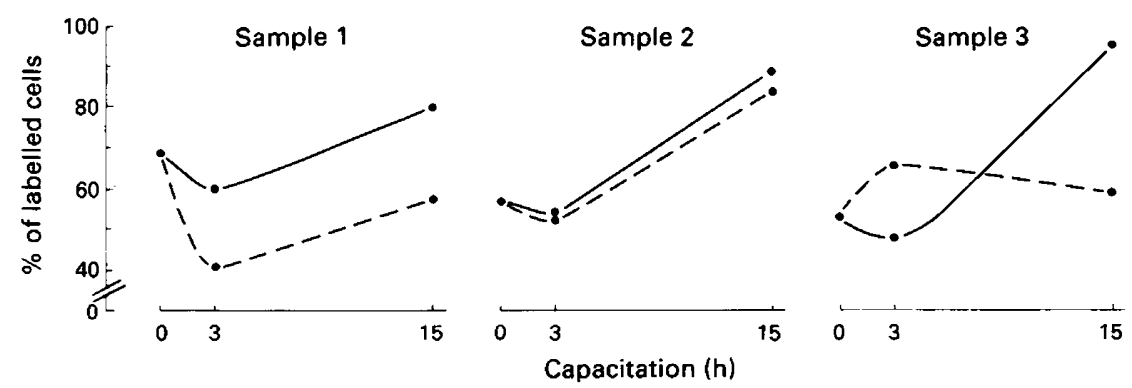

Fig. 7. Temperature dependence of the antigen changes during capacitation. Three different ejaculates were incubated at $37^{\circ} \mathrm{C}$ (broken line) and room temperature (solid line). Aliquants were removed at the times shown and immunostained with the a-HS 1A.l monoclonal antibody.

Whether the changes in the size of the labelled population and in the antibody binding pattern required energy or not was investigated by incubating spermatozoa in capacitation medium in the absence or presence of 1,4-dinitrophenol, an uncoupler of oxidative phosphorylation. Data from two experiments are shown in Fig. 6. Without dinitrophenol the positive population increased overall, as did P, E and D labelled cells. In the presence of dinitrophenol the existence of different phenomena was evident: (1) an energy-independent antigen mobility, shown by the increased percentage of P, E and D labelling; (2) an energy-independent disappearance of the antigen, visualized by the decreased labelled population; and (3) an energy-dependent revealing of new epitopes: no augmentation of the total percentage of positive cells was noted. The A2 pattern was characteristic for dinitrophenol-treated cells. 

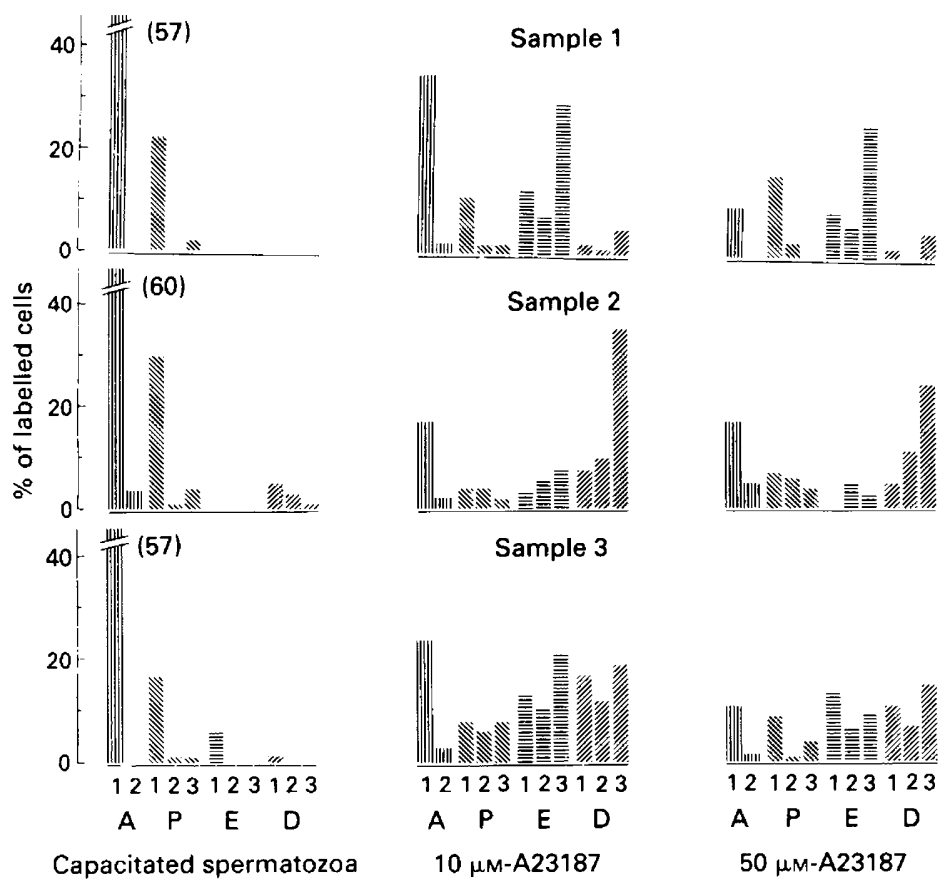

Fig. 8. Variability in the redistribution of the HS 1A.1 antigen on human spermatozoa (see Fig. 1) from three different ejaculates $(1,2,3)$, during incubation in a capacitation medium or undergoing the acrosome reaction induced for $15 \mathrm{~min}$ with 10 and $50 \mu \mathrm{M}-\mathrm{A} 23187$. The antigen migrated predominantly to the equatorial segment (E labelling, Sample 1) or equatorial segment + postacrosome (D labelling, Sample 2) or was evenly distributed between both (E and D labelling, Sample 3).

Incubation of spermatozoa at different temperatures showed that the total percentage of labelled cells was often greater for gametes incubated at room temperature than when incubated at $37^{\circ} \mathrm{C}$ (Fig. 7). The migration of the antigen was effective at $37^{\circ} \mathrm{C}$ and poor at room temperature (data not shown).

\section{Lateral mobility of the antigen at the start of induction of the acrosome reaction in vitro}

When an acrosome reaction was induced in vitro with the ionophore A23187 in the presence of $\mathrm{Ca}^{2+}, \mathrm{P}, \mathrm{E}$ and D binding patterns could be seen (Fig. 8). DMSO alone, at the concentration used, had no effect on the antigen migration. The antibody binding patterns were constant whether the spermatozoa were capacitated for 1 or $6 \mathrm{~h}$ or not capacitated. The new antigen localization was often alike in successive ejaculates of the same donor and could be distinct in ejaculates from different individuals. A smaller percentage of labelled cells, less intense fluorescent staining and little or no migration have been observed in patients consulting for infertility and in healthy donors affected by a disease such as influenza.

The new patterns of the antibody binding could have resulted from a migration of the HS 1A.1 antigen or from the disclosing of new epitopes. To test these possibilities the acrosome reaction was induced in cells in which the antigen was or was not tagged with the monoclonal antibody. The results from two experiments (Fig. 9) indicated that the new antibody patterns resulted from a lateral diffusion of the antigen and that the antigen could move even when tagged with the anti- 
Sample 1

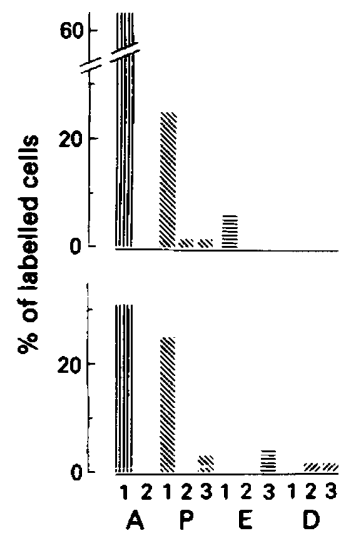

(a)

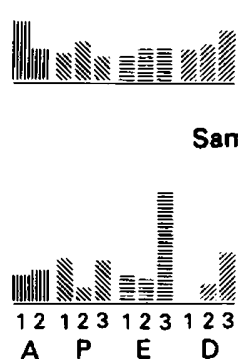

(b)
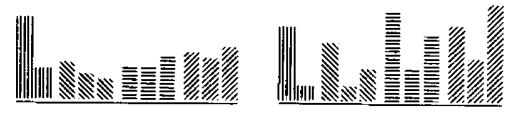

Sample 2

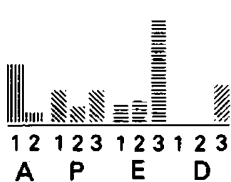

(c)

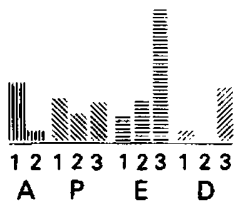

(d)

Fig. 9. Percentage of positive cells and antibody binding patterns (see Fig. 1) on cells from two different ejaculates $(1,2)$, as detected by indirect immunofluorescence. Aliquants of spermatozoa were processed through: (a) incubation with a-HS $1 \mathrm{~A} .1$, washing and incubation with FITC-GAM; (b) acrosome reaction induced with $25 \mu \mathrm{M}-\mathrm{A} 23187$ for $30 \mathrm{~min}$ at $37^{\circ} \mathrm{C}$, washing and immunolabelling as in (a); (c) incubation with a-HS 1A.1, washing, acrosome reaction as in (b), washing and incubation with FITC-GAM; (d) incubation with a-HS 1A.1, acrosome reaction by adding double strength medium to compensate for the presence of hybridoma supernatant, washing and incubation with FITC-GAM. The antigen migrated to the equatorial segment and equatorial segment + postacrosome (E and D labelling, Sample 1) or predominantly to the equatorial segment (E labelling, Sample 2).

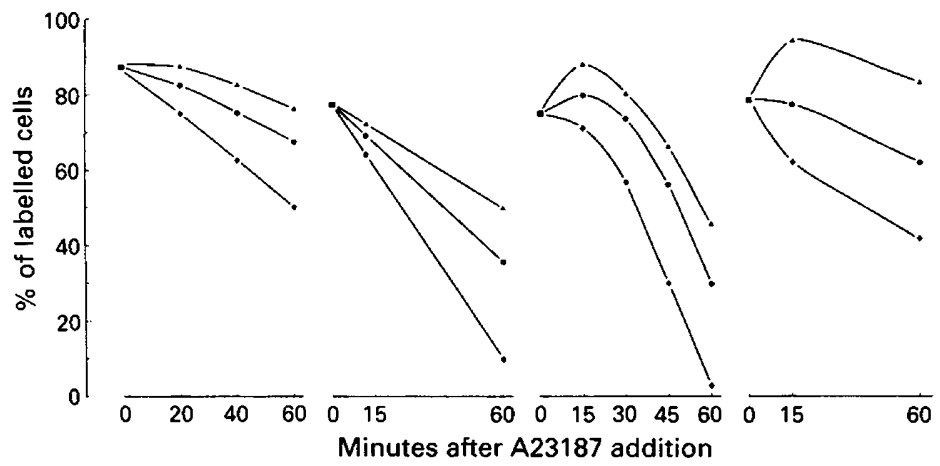

Fig. 10. The kinetics of changes in the antigen-antibody binding in spermatozoa from four different ejaculates. The acrosome reaction of capacitated gametes $(\boldsymbol{\nabla})$ was induced with 10 $(\Delta), 50(\bullet)$ or $100(\diamond) \mu \mathrm{M}-\mathrm{A} 23187$. Aliquants were removed at the times shown, washed and immunostained with a-HS 1A.1 monoclonal antibody followed by FITC-GAM.

body. When the acrosome reaction was induced for longer periods or with a greater concentration of A23187, the percentage of labelled cells decreased dramatically in Exp. (b), but much less in Exps (c) and (d).

Induction of the acrosome reaction with concentrations of A23187 from 5 to $50 \mu \mathrm{M}$ gave similar binding pattern for each individual ejaculate (Fig. 8). The antigen migration could be induced with only $5 \mu \mathrm{M}$ ionophore for $5 \mathrm{~min}$, while a concentration of $1 \mu \mathrm{M}$ was often ineffective; 10 and $<10 \mu \mathrm{M}$ 
Fig. 11

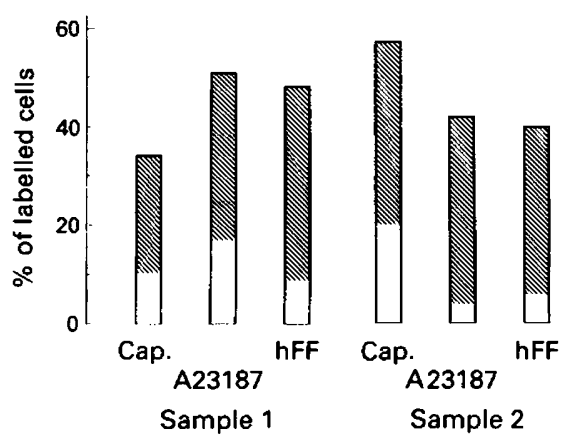

Fig. 12

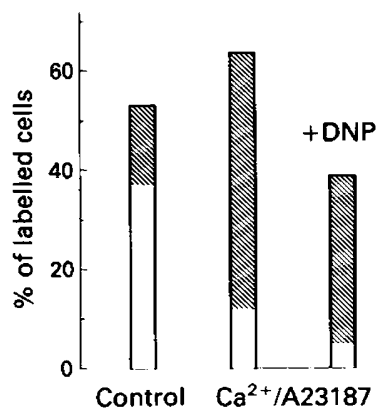

Fig. 11. Comparison of the effect of human follicular fuid (hFF) and A23187 on a-HS 1A.1 antibody binding pattern. Capacitated for $15 \mathrm{~h}$ human spermatozoa (Cap.) from two different ejaculates $(1,2)$ were incubated in $500 \mu \mathrm{l} \mathrm{hFF}$ or $50 \mu \mathrm{M}$-A23187 for $10 \mathrm{~min}$ at $37^{\circ} \mathrm{C}$, washed and then immunostained. The total percentage of positive cells included Al and A2 labelling (open bars) and P, E and D labelling (closed bars).

Fig. 12. Energy dependence of the changes in the a-HS $1 \mathrm{~A} .1$ antibody binding pattern after $\mathrm{Ca}^{2+} / \mathrm{A} 23187$ treatment. Human spermatozoa (Control, before treatment) were incubated in

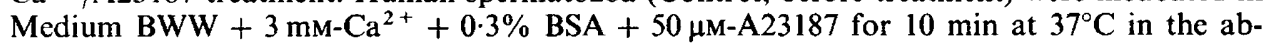
sence or presence of $10 \mathrm{~mm}-\mathrm{DNP}$. The Al and A2 labelling (open bars) and P, E and D labelling (closed bars) are indicated.

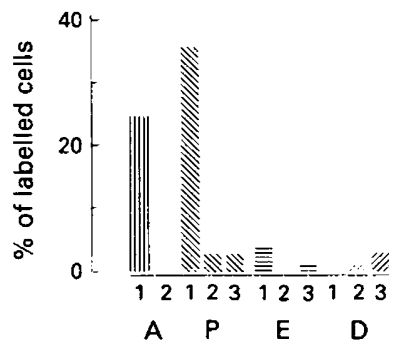

Capacitated spermatozoa

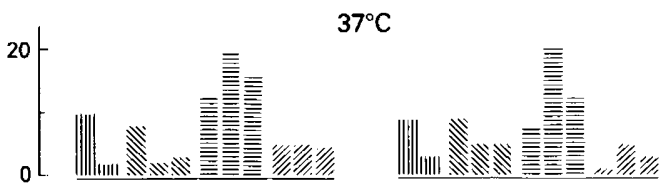

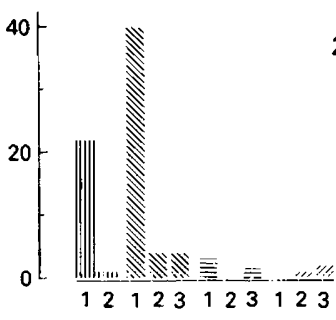

A $\underset{5 \mu \mathrm{M}-\mathrm{A} 23187}{\mathrm{E}} \mathrm{D}$ $22^{\circ} \mathrm{C}$

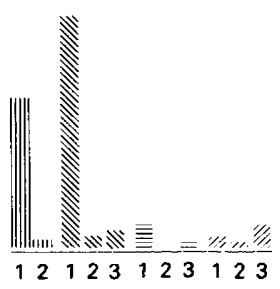

A $\underset{10 \mu M-A 23187}{P} D$

Fig. 13. Temperature dependence of the HS 1A.1 antigen migration. Capacitated human spermatozoa were incubated at $22^{\circ} \mathrm{C}$ or $37^{\circ} \mathrm{C}$ with 5 or $10 \mu \mathrm{M}-\mathrm{A} 23187$ for $10 \mathrm{~min}$. See Fig. 1 for binding patterns.

concentrations increased the total percentage of labelled cells (Fig. 10). Increasing the concentration of A23187 and the duration of the treatment caused the disappearance of the antigenantibody binding, with characteristic individual donor response of the rate of this phenomenon (Fig. 10)

When A23187 was added in absence of $\mathrm{Ca}^{2+}$, migration of the fluorescent label was not observed. In the presence of $\mathrm{Ca}^{2+}$, when ionomycin was substituted for A23187, similar antigen 


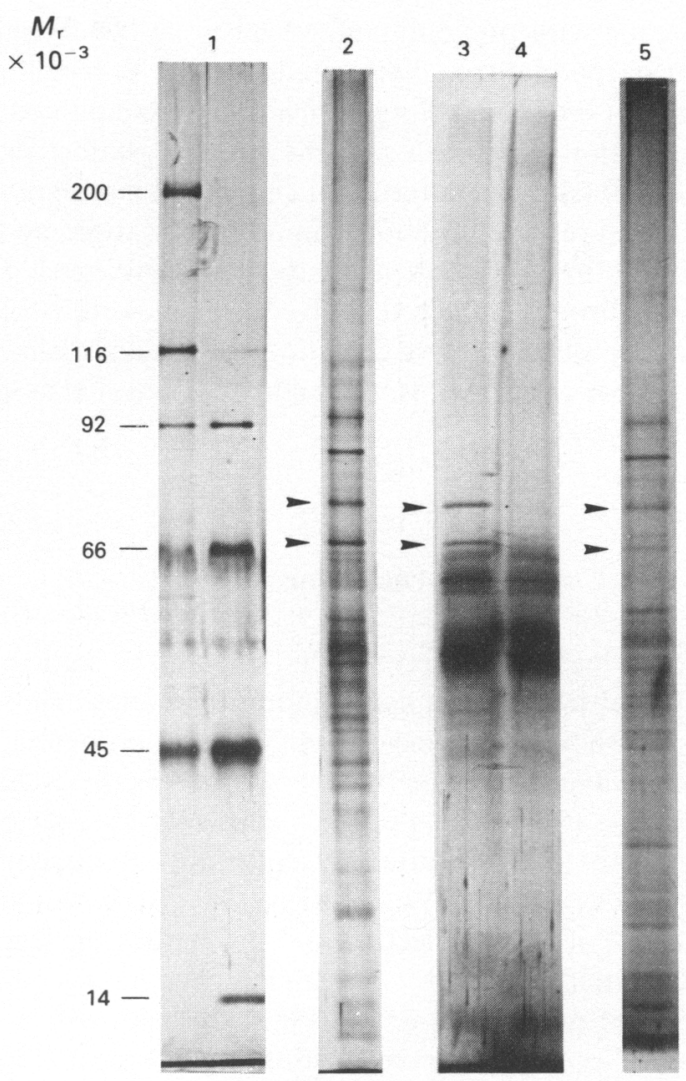

Fig. 14. Identification of the HS 1A.1 antigen (arrowhead) by immunoprecipitation. All samples were submitted to SDS-PAGE under reducing conditions and silver stained after DTT treatment unless otherwise stated. Molecular weight standards (1); whole human sperm proteins (2); HS 1A.1 antigen (3), run in parallel with control for the migration of the monoclonal antibody and the Protein A (4); whole human sperm proteins, silver stained after periodic acid treatment (5).

migration was observed, ionomycin being effective at concentration of $1 \mu \mathrm{M}$. Human follicular fluid was able to induce changes similar to the A23187 effect in the antibody binding pattern and in the size of the positive population (Fig. 11).

The migration of the HS 1A.1 antigen was temperature-dependent. Incubation with A23187, regardless of the concentration, induce a new antibody binding pattern at $37^{\circ} \mathrm{C}$ but not at room temperature $\left(22^{\circ} \mathrm{C}\right)$ (Fig. 13).

The energy-dependence of the phenomena induced by $\mathrm{Ca}^{2+} / \mathrm{A} 23187$ treatment was investigated by adding dinitrophenol in the media. The results in Fig. 12 showed that the antigen migration and the antigen disappearance were energy-independent phenomena, whereas the revealing of new epitopes required energy.

\section{Molecular identity of the HS 1 A.1 antigen}

When the immunoprecipitated HS 1A.1 antigen was submitted to dissociating PAGE, two bands were detected at $M_{\mathrm{r}}$ of 76000 and 67000 , as calculated from three different experiments (Fig. 14,3). The intensity of the stained bands was affected when semen samples with different percentages of positive cells were immunoprecipitated. The bands were the same whether the antigen of 
freshly ejaculated spermatozoa with predominant Al labelling (as detected by indirect immunofluorescence) or capacitated spermatozoa with predominant $\mathbf{P}$ labelling or acrosome reacted spermatozoa with predominant $E$ or D labelling were immunoprecipitated. The two subunits of the antigen were amongst the major components of the proteins stained with silver (Fig. 14,2) or Coomassie brilliant blue R 250 (similar pattern, not shown). When seminal plasma samples from normal or vasectomized men were submitted to immunoprecipitation, no bands were observed.

In gels treated with dithiothreitol, protein bands were developed, but in gels treated with periodic acid or potassium dichromate/nitric acid glycoproteins were visualized. The periodic acid allows greater sensitivity of the silver staining than does potassium dichromate/nitric acid, and so we used preferentially the former treatment. Both bands were detected as glycoprotein, the band of $M_{\mathrm{r}} 67000$ being poorly visualized (Fig. 14,5).

\section{Discussion}

Cell function requires that cell membranes have both dynamic and static properties. Restriction of lateral mobility is a common observation, most membrane proteins exhibiting immobile fractions suggested to be related to the subjacent cytoskeleton. The membrane fluidity varies within lateral domains in the plane of the bilayer as well as transversely across the membrane. Lateral diffusion of proteins (reviewed by Peters, 1985) occurs in the presence or absence of ligands. Many ligands that bind more or less uniformly to a cell surface receptor are subsequently accumulated within a much smaller area of the surface (Pastan \& Willingham, 1981; Berlin \& Oliver, 1982; Koppel et al., 1982), the formation of 'caps' of various lectins and antibodies on leucocytes being a familiar example. Antibody-induced patching of sperm antigen has been reported for rabbit (O'Rand, 1977; O'Rand \& Romrell, 1981) and rat (Gaunt et al., 1983) spermatozoa. Lateral migrations in the absence of bound ligand have been suggested by Geiduschek \& Singer (1979), Chow \& Poo (1982), McCaig \& Robinson (1982) and Rogalski \& Bouck (1982). Myles \& Primakoff (1984) observed, in the guinea-pig, migration of an antigen from the posterior tail on to the anterior tail during capacitation, and migration of another one from the posterior head region on to the inner acrosomal membrane during the acrosome reaction, both in almost $100 \%$ of the sperm population. A part of the last one, PH-20 protein, functioning in sperm adhesion to the egg zona pellucida (Primakoff et al., 1985), appears to be sequestered on an intracellular membrane before being exposed by the sperm exocytosis (Cowan et al., 1986).

Our results show that the HS 1A.1 antigen moves spontaneously (that is, in the absence of ligand) during changes in the functional state of spermatozoa. Ejaculated spermatozoa characteristically have very stable membranes (Darin-Bennet et al., 1976; Darin-Bennet \& White, 1977; Demel et al., 1972; Demel \& De Kruyff, 1976; Holt \& North, 1985). During capacitation removal and/or alteration of surface-bound components occur(s) (see reviews by O'Rand, 1979; Rogers \& Bentwood, 1982), as well as alteration of surface charge, levels of membrane cholesterol and structure of membrane phospholipids (reviewed by Langlais \& Roberts, 1985), leading to an increase in the permeability towards extracellular $\mathrm{Ca}^{2+}$ and in plasma membrane fluidity. The last could be associated with capricious and fluctuating localization of the HS 1A.1 antigen patches over the sperm head. The sperm membrane destabilization culminates in the acrosome reaction, for which an extensive rearrangement of intramembranous particles, especially in the plasma membrane, has been reported as an early event (Jamil et al., 1982; Fléchon, 1985; Fléchon et al., 1986), probably related to increased plasma membrane fluidity (Bearer \& Friend, 1982; Friend, 1984). During $\mathrm{Ca}^{2+} / \mathrm{A} 23187$ treatment a part of the HS 1A.1 antigen migrates on a time scale of only a few minutes, i.e. at the very start of the acrosome reaction before its completion (Russell et al., 1979). This probably reflects integral constituent changes which progressively induce local lateral heterogeneity of the plasma membrane leading up to fusion. 
The relocation of the HS 1A.1 antigen seems actually to be related with the first events of the acrosome reaction in human spermatozoa. The antibiotic A23187, a carboxylic acid ionophore, known to transport divalent cations across cell membranes (Babcock et al., 1976), is used in many species to induce artificially a $\mathrm{Ca}^{2+}$-dependent acrosome reaction supposed to be similar to the physiologically induced one (see discussions by Shams-Borhan \& Harrison, 1981; Huneau et al., 1984). Nevertheless differences can be detected (Tesařik, 1985), probably due to over-stimulation, the $\mathrm{Ca}^{2+}$ influx being greater after A23187 treatment. To investigate that the entry of $\mathrm{Ca}^{2+}$ into the sperm cell actually induced the observed changes in the antibody-binding pattern, we used ionomycin, an ionophoric polyether antibiotic, more effective than A23187 as a mobile ion carrier for $\mathrm{Ca}^{2+}$. Both ionophores, and human follicular fluid, induced similar antibody binding patterns.

The relocation of HS 1A.1 antigen does not appear to require cellular energy and is consistent with models involving diffusion and trapping, as does the redistribution of lectin receptors in regions of cell-cell contact (Chow \& Poo, 1982) or of the acetylcholine receptor (Fraser \& Poo, 1982). The progressive appearance of clearly defined $E$ and $D$ patterns is in agreement with this model. At the moment we do not know how the mobile antigen becomes anchored in the sperm membrane around the equatorial and posterior segments. Direct interaction between membrane proteins and the subjacent skeleton is possible, the presence of cytoskeletal elements being reported by Escalier (1984) and Virtanen et al. (1984), as well as their conformational changes after $\mathrm{Ca}^{2+} /$ A23187 treatment (Jamil, 1984). Alternatively, molecular segregation could be maintained by thermodynamic partitioning into a physico-chemically distinct membrane domain. A local heterogeneity of plasma membrane structures seems to be possible.

A molecular model of the observed changes can be proposed. In ejaculated spermatozoa the integral antigenic glycoprotein, associated with peripheral components, has a patchy distribution. The removal and/or transformation of the sperm coat allows an energy-dependent unmasking of new epitopes, the peripheral components no longer sterically hindering the antibody binding. The transformation of large patches into a multitude of small spots fits perfectly with the model proposed by O'Rand (1979) for intrinsic mobile glycoproteins associated with peripheral components. The antigen is able to migrate, an energy-independent lateral diffusion until accumulation in specific patterns. These changes are under $\mathrm{Ca}^{2+}$ control or are associated with a $\mathrm{Ca}^{2+}$-activated process. Moreover, a redistribution of intramembranous particles has been reported to occur in $\mathrm{Ca}^{2+}$-free medium (Friend et al., 1977; Yanagimachi \& Suzuki, 1985). The complex biochemical events involved in capacitation and in the start of the acrosome reaction are probably differently affected by the presence of calcium ion, as reported for various stages of fertilization (Yanagimachi, 1982).

Labelling of viable cells was chosen to avoid antigen denaturation by fixation (Hancock et al., 1982; Walker et al., 1984; Villarroya \& Scholler, 1986a). The use of viable cells can introduce some sources of error which were overcome by careful controls. We achieved a parallel assessment of the ultrastructural localization of the antigen by electron microscopy.

The patchy distribution of the HS 1A.1 antigen in a single cell is a confirmation of the well known concept of regional heterogeneity of the sperm plasma membrane (see 'Introduction'). On the other hand, as far as we are aware, ours is the first observation of differences in the immobilization patterns after lateral diffusion of an integral membrane component, differences between spermatozoa from the same ejaculate or semen samples from different donors.

We wish to emphasize the tremendous inter- and intra-individual variability of our findings. The heterogeneity amongst different semen samples and among cells within any one sample is a well-known fact for any researcher in the area of mammalian fertilization. The acrosome reaction in individual spermatozoa takes place asynchronously (Singhas \& Oliphant, 1978; Florman \& Storey, 1982; Fléchon et al., 1986). Likewise, rat eggs display a variety of surface changes during sperm incorporation (Battaglia \& Gaddum-Rosse, 1984). It is therefore not surprising to observe that, in probably different subpopulations of gametes, proteins embedded in the sperm membrane have dissimilar migration patterns. Their accumulation, or otherwise, around the equatorial 
segment and the postacrosome, sites of initial sperm-egg contact and fusion, probably reveals differences in the physico-chemical properties of the sperm membrane. The observations reported in this paper do not, however, permit speculation on its functional significance.

We thank B. Mérand for excellent technical assistance and D. Huneau for the electron microscopy.

\section{References}

Anderson, R.G.W., Brown, M.S., Beisiegel, U. \& Goldstein, J.L. (1982) Surface distribution and recycling of the low density lipoprotein receptor as visualized with antireceptor antibodies. J. Cell Biol. 93, 523-531.

Babcock, D.F., First, N.L. \& Lardy, H.A (1976) Action of ionophore A23187 at the cellular level. J. biol. Chem. 251, 3881-3886.

Battaglia, D.E. \& Gaddum-Rosse, P. (1984) Rat eggs normally exhibit a variety of surface phenomena during fertilization. Gamete Res. 10, 107-118.

Bearer, E.L. \& Friend, D.S. (1982) Modifications of anionic-lipid domains preceding membrane fusion in guinea pig sperm. J. Cell Biol. 92, 604-615.

Bedford, J.M. \& Cooper, G.W. (1978) Membrane fusion events in fertilization of vertebrate eggs. In Cell Surface Reviews, vol. 5, Membrane Fusion, pp. 65-125. Eds G. Poste \& G. L. Nicolson. North Holland, Amsterdam.

Bellvé, A.R. \& O'Brien, D.A. (1983) The mammalian spermatozoon: structure and temporal assembly. In Mechanism and Control of Animal Fertilization, pp. 55-137. Ed. J. F. Hartman. Academic Press, New York.

Berlin, R.D. \& Oliver, J.M. (1982) The movement of bound ligands over cell surfaces. J. theor. Biol. 99, 69-80.

Biggers, J.D., Whitten, W.K. \& Whittingham, D.G. (1971) The culture of mouse embryos in vitro. In Methods in Mammalian Embryology, pp. 86-116. Ed. J. C. Daniel, Jr. Freeman, San Francisco.

Chow, I. \& Poo, M.-M. (1982) Redistribution of cell surface receptors induced by cell-cell contact. $J$. Cell Biol. 95, 510-518.

Cowan, A.E., Primakoff, P. \& Myles, D.G. (1986) Sperm exocytosis increases the amount of $\mathrm{PH}-20$ antigen on the surface of guinea pig sperm. J. Cell Biol. 103, 1289-1297.

Darin-Bennet, A. \& White, I.G. (1977) Influence of the cholesterol content of mammalian spermatozoa on susceptibility to cold-shock. Cryobiology 14, 466470 .

Darin-Bennet, A., Poulos, A. \& White, I.G. (1976) The fatty acid composition of the major phosphoglycerides of ram and human spermatozoa. Andrologia $\mathbf{8 ,}$ $37-45$.

Demel, R.A. \& De Kruyff, B. (1976) The function of sterols in membranes. Biochim. Biophys. Acta 457, $109-132$.

Demel, R.A., Geurts Van Kessel, W.S.M. \& Van Deenen, L.L.M. (1972) The properties of polyunsaturated lecithins in monolayers and liposomes and the interactions of these lecithins with cholesterol. Biochim. Biophys. Acta 166, 26-40.
Dzandu, J.K., Deh, M.E., Barratt, D.L. \& Wise, G.E. (1984) Detection of erythrocyte membrane proteins, sialoglycoproteins, and lipids in the same polyacrylamide gel using a double-staining technique. Proc. natn. Acad. Sci. U.S.A. 81, 1733-1737.

Escalier, D. (1984) The cytoplasmic matrix of the human spermatozoon cross-filaments link the various cell components. Biol. Cell 51, 347-364.

Eschenbruch, M. \& Bürk, R.R. (1982) Experimentally improved reliability of uitrasensitive silver staining of protein in polyacrylamide gels. Analyt. Biochem. 125, 96-99.

Fléchon, J.-E. (1985) Sperm surface changes during the acrosome reaction as observed by freeze-fracture. Am. J. Anat. 174, 239-248.

Fléchon, J.-E., Harrison, R.A.P., Fléchon, B. \& Escaig, J. (1986) Membrane fusion events in the $\mathrm{Ca}^{2+}$ ionophore-induced acrosome reaction of ram spermatozoa. J. Cell Sci. 81, 43-63.

Florman, H.M. \& Storey, B.T. (1982) Mouse gamete interactions: the zona pellucida is the site of the acrosome reaction leading to fertilization. Devl Biol. 91, 121-130.

Fraser, S.E. \& Poo, M.-M. (1982) Development, maintenance, and modulation of patterned membrane topography: models based on the acetylcholine receptor. Curr. Top. devl Biol. 17, 77-100.

Friend, D.S. (1982) Plasma-membrane diversity in a highly polarized cell. J. Cell Biol. 93, 243-249.

Friend, D.S. (1984) Membrane organization and differentiation in the guinea pig spermatozoon. In Ultrastructure of Reproduction, pp. 75-85. Eds J. Van Blerkom \& P. M. Motta. Martinus Nijhoff, Boston.

Friend, D.S., Orci, L., Perrelet, A. \& Yanagimachi, R. (1977) Membrane particle changes attending the acrosome reaction in guinea pig spermatozoa. $J$. Cell Biol. 74, 561-577.

Fujita, M., Kawai, K., Asano, S. \& Nakao, M. (1973) Protein components of two different regions of an intestinal epithelial cell membrane. Regional singularities. Biochim. Biophys. Acta 307, 144-151.

Gaunt, S.J., Brown, C.R. \& Jones, R. (1983) Identification of mobile and fixed antigens on the plasma membrane of rat spermatozoa using monoclonal antibodies. Expl Cell Res. 144, 275-284.

Geiduschek, J.B. \& Singer, S.J. (1979) Molecular changes in the membrane of mouse erythroid cells accompanying differentiation. Cell 16, 149-163.

Hancock, W.W., Becker, G.J. \& Atkins, R.C. (982) A comparison of fixatives and immunohistochemical technics for use with monoclonal antibodies to cell surface antigens. Am. J. clin. Path. 78, 825-831.

Heukeshoven, J. \& Dernick, R. (1985) Simplified method for silver staining of proteins in polyacrylamide gels 
and the mechanism of silver staining. Electrophoresis 6, 103-112.

Holt, W.V. \& North, R.D. (1985) Determination of lipid composition and thermal phase transition temperature in an enriched plasma membrane fraction from ram spermatozoa. J. Reprod. Fert. 73, 285-294.

Huneau, D., Harrison, R.A.P. \& Fléchon, J.-E. (1984) Ultrastructural localization or proacrosin and acrosin in ram spermatozoa. Gamete Res. 9, 425440.

Jamil, K. (1984) Plasma membrane cytoskeletal complex of the mammalian spermatozoa. Archs Androl. 13, 177-193.

Jamil, K., White, I.G. \& Warte, D.M. (1982) Calcium ionophore A23187 as a probe for freeze-fracture studies of membrane changes in the head of human spermatozoa. Archs Androl. 8, 1-9.

Karnovsky, M.J., Kleinfeld, A.M., Hoover, R.L. \& Klausner, R.D. (1982) The concept of lipid domains in membranes. J. Cell Biol. 94, 1-6.

Koehler, J.K. (1978) The mammalian sperm surface: studies with specific labeling techniques. Int. Rev. Cytol. 54, 73-108.

Koehler, J.K. (1981) Lectins as probes of the spermatozoon surface. Archs Androl. 6, 197-217.

Koppel, D.E., Oliver, J.M. \& Berlin, R.D. (1982) Surface functions during mitosis. III. Quantitative analysis of ligand-receptor movement into the cleavage furrow: diffusion vs. flow. J. Cell Biol. 93, 950-960.

Laemmli, U.K. (1970) Cleavage of structural proteins during the assembly of the head of bacteriophage T4. Nature, Lond. 227, 680-685.

Langlais, J. \& Roberts, K.D. (1985) A molecular membrane model of sperm capacitation and the acrosome reaction of mammalian spermatozoa. Gamete Res. 12, $183-224$.

McCaig, C.D. \& Robinson, K.R. (1982) The distribution of lectin receptors on the plasma membrane of the fertilized sea urchin egg during first and second cleavage. Devl Biol. 92, 197-202.

Morrissey, J.H. (1981) Silver stain for proteins in polyacrylamide gels: a modified procedure with enhanced uniform sensitivity. Analyt. Biochem. 117, 307-310.

Myles, D.G. \& Primakoff, P. (1984) Localized surface antigens of guinea pig sperm migrate to new regions prior to fertilization. J. Cell Biol. 99, 1634-1641.

Nicolson, G.L. (1982) Mammalian sperm plasma membrane. In Prospects for Sexing Mammalian Sperm, pp. 5-13. Eds R. P. Amann \& G. E. Seidel. Colorado Assoc. Univ. Press, Boulder.

O'Rand, M.G. (1977) Restriction of a sperm surface antigen's mobility during capacitation. Devl Biol. 55, $260-270$.

O'Rand, M. (1979) Changes in sperm surface properties correlated with capacitation. In The Spermatozoon, pp. 195-204. Eds D. W. Fawcett \& J. M. Bedford. Urban \& Schwarzenberg, Inc., Baltimore.

O'Rand, M.G. \& Romrell, L.J. (1981) Localization of a single sperm membrane autoantigen (RSA-1) on spermatogenic cells and spermatozoa. Devl Biol. 84, $322-331$.

Pastan, I.H. \& Willingham, M.C. (1981) Journey to the center of the cell: role of the receptosome. Science, N.Y. 214, 504-509.

Peters, R. (1985) Lateral mobility of proteins in membranes. In Structure and Properties of Cell
Membranes, Vol. 1, pp. 35-50. Ed. Gh. Benga. CRC Press, Boca Raton.

Primakoff, P. \& Myles, D.G. (1983) A map of the guinea pig sperm surface constructed with monoclonal antibodies. Devl Biol. 98, 417-428.

Primakoff, P., Hyatt, H. \& Myles, D.G. (1985) A role for the migrating sperm surface antigen $\mathrm{PH}-20$ in guinea pig sperm binding to the egg zona pellucida. J. Cell Biol. 101, 2239-2244.

Rogalski, A.A. \& Bouck, G.B. (1982) Flagellar surface antigens in Euglena: immunological evidence for an external glycoprotein pool and its transfer to the regenerating flagellum. J. Cell Biol. 93, 758-766.

Rogers, J.B. \& Bentwood, B.J. (1982) Capacitation, acrosome reaction, and fertilization. In Biochemistry of Mammalian Reproduction, pp. 203-230. Eds L. Zaneveld \& R. T. Chatterton. J. Wiley, New York.

Russell, L., Peterson, R.N. \& Freund, M. (1979) Morphologic characteristics of the chemically induced acrosome reaction in human spermatozoa. Fert. Steril. 32, 87-92.

Shams-Borhan, G. \& Harrison, R.A.P. (1981) Production, characterization, and use of ionophore-induced, calcium-dependent acrosome reaction in ram spermatozoa. Gamete Res. 4, 407-432.

Singer, S.J. \& Nicolson, G.L. (1972) The fluid mosaic model of the structure of cell membranes. Sciences, N.Y. 175, 720-731.

Singhas, C.A. \& Oliphant, G. (1978) Ultrastructural observations of the time sequence of induction of acrosomal membrane aiterations by ovarian follicular fluid. Fert. Steril. 29, 194-203.

Tea, N.T., Jondet, M. \& Scholler, R. (1983) A 'Migration-gravity sedimentation' method for collecting motile spermatozoa from human semen. In In vitro Fertilization, Embryo Transfer and Early Pregnancy, pp. 117-120. Eds R. F. Harrison, J. Bonnar \& W. Thompson. MTP Press Ltd, Lancaster.

Tesařik, J. (1985) Comparison of acrosome reactioninducting activities of human cumulus oophorus, follicular fluid and ionophore A23187 in human sperm populations of proven fertilizing ability in vitro. J. Reprod. Fert. 74, 383-388.

Villarroya, S. \& Scholler, R. (1986a) Regional heterogeneity of human spermatozoa detected with monoclonal antibodies. J. Reprod. Fert. 76, 435-447.

Villarroya, S. \& Scholler, R. (1986b) Migration of an acrosomal surface antigen of human spermatozoa during capacitation and in-vitro induction of acrosome reaction. Human Reprod., Suppl. p. 3, Abstr. 8.

Virtanen, I., Badley, R.A., Paasivuo, R. \& Lehto, V.-P. (1984) Distinct cytoskeletal domains revealed in sperm cells. J. Cell Biol. 99, 1083-1091.

Walker, W.S., Beelan, R.H.J., Buckley, P.J., Melvin, S.L. \& Yen, S.-E. (1984) Some fixation reagents reduce or abolish the detectability of la-antigen and HLA-DR on cells. J. Immunol. Meth. 67, 89-99.

Wall, D.A. \& Hubbard, A.L. (1981) Galactose-specific recognition system of mammalian liver: receptor distribution on the hepatocyte cell surface. J. Cell Biol. 90, 687-696.

Wisher, M.H. \& Evans, W.H. (1975) Functional polarity of the rat hepatocyte surface membrane. Isolation and characterization of plasma-membrane subfraction from the blood-sinusoidal, bile-canalicular, and 
contiguous surfaces of the hepatocyte. Biochem. J. 146, 375-388.

Wolf, D.E., Scott, B.K. \& Millette, C.F. (1986) The development of regionalized lipid diffusibility in the germ cell plasma membrane during spermatogenesis in the mouse. J. Cell Biol. 103, 1745-1750.

Yanagimachi, R. (1981) Fertilization and embryonic development in vitro. In Mechanisms of Fertilization in Mammals, pp. 82-182. Eds L. Mastroianni, Jr \& J. D. Biggers. Plenum Press, New York.
Yanagimachi, R. (1982) Requirement of extracellular calcium ions for various stages of fertilization and fertilization-related phenomena in the hamster. Gamete Res. 5, 323-344.

Yanagimachi, R. \& Suzuki, F. (1985) A further study of lysolecithin-mediated acrosome reaction of guinea pig spermatozoa. Gamete Res. 11, 29-40.

Received 17 November 1986 